\title{
Mechanisms of Laser-Induced Reactions of Stacked Benzene Molecules: A Semiclassical Dynamics Simulation and CASSCF Calculation
}

\author{
Kunxian Shu, ${ }^{1}$ Jie Zhao, ${ }^{1}$ Shuai Yuan, ${ }^{1}$ Yusheng Dou, ${ }^{2}$ and Glenn V. Lo ${ }^{2}$ \\ ${ }^{1}$ Institute of Bioinformatics, Chongqing University of Posts and Telecommunications, Chongqing 400065, China \\ ${ }^{2}$ Department of Physical Sciences, Nicholls State University, P.O. Box 2022, Thibodaux, LA 70310, USA
}

Correspondence should be addressed to Shuai Yuan; yuanshuai@cqupt.edu.cn and Yusheng Dou; yusheng.dou@nicholls.edu

Received 8 May 2014; Accepted 27 June 2014; Published 27 October 2014

Academic Editor: Fuli Li

Copyright (C) 2014 Kunxian Shu et al. This is an open access article distributed under the Creative Commons Attribution License, which permits unrestricted use, distribution, and reproduction in any medium, provided the original work is properly cited.

\begin{abstract}
The response to ultrashort laser pulses of two stacked benzene molecules has been studied by semiclassical dynamics simulation; two typical pathways were found following excitation of one of the benzene molecules by a $25 \mathrm{fs}$ (FWHM), $4.7 \mathrm{eV}$ photon. With a fluence of $40.49 \mathrm{~J} / \mathrm{m}^{2}$, the stacked molecules form a cyclobutane benzene dimer; the formation of the two covalent bonds linking two benzenes occurs asynchronously after the excimer decays to electronic ground state. With a fluence of $43.26 \mathrm{~J} / \mathrm{m}^{2}$, only one bond is formed, which breaks about $50 \mathrm{fs}$ after formation, followed by separation into the two molecules. The deformation of benzene ring is found to play an important role in the bond cleavage.
\end{abstract}

\section{Introduction}

The photocycloaddition reactions of unsaturated double bond complexes are of theoretical interest because these reactions are involved in DNA photodamage [1-4] and organic synthesis $[5,6]$. The best known examples are the $[2+2]$ photocycloaddition (forming either cyclobutanes or four-membered heterocycles) and excited state $[4+4]$ cycloadditions that produce cyclooctadiene compounds.

Although quite (thermally) stable, benzene molecules can become quite reactive when being photoexcited; they can be transformed to benzvalene $[7,8]$ and fulvene when being excited to the first singlet $\left(S_{1}\right)$ excited state or to Dewar benzene $[9,10]$ when being excited to the second singlet $\left(S_{2}\right)$ excited state. Benzene can be involved in a photocycloaddition reaction with an alkene molecule. The reactions can be classified into three categories $[5,6]:[2$ + 2] (or ortho), [3 + 2] (or meta), and [4+2] (or para) photocycloadditions. Photocycloadditions of benzene and an alkene are usually triggered by the photoexcitation of the benzene molecule. If the $S_{1}$ state of benzene is involved, only meta addition is allowed to occur in a concerted fashion according to molecular orbital symmetry rules [11, 12]. The formation of ortho- and para-cycloadducts can be interpreted as being due to (i) charge transfer processes, (ii) nonconcerted mechanism, and (iii) excitation to the $S_{2}$ state. Clifford et al. found [13] that for the benzene plus ethylene system cycloadditions could take place from $S_{1}$ state without barrier through a conical intersection (CI), which is common to all three cycloadducts. This low energy CI results from the formation of one $\mathrm{C}-\mathrm{C}$ bond between benzene and ethylene. Their subsequent studies [14] suggest that CI seam between $S_{1}$ and $S_{0}$ could control chemical selectivity in the photocycloaddition of benzene and ethylene.

Cycloadditions, $[4+2]$ and $[4+4]$, are also observed between polycondensed aromatic compounds such as naphthalene, anthracene, and their derivatives. The $[4+2]$ cycloaddition (photo-Diels-Alder reaction) [15-18] is frequently observed with naphthalene derivatives. $[4+4]$ photocycloadditions are often observed in two-arene systems which are connected by a saturated bridge (such as $-\mathrm{CH}_{2}-$ $\mathrm{CH}_{2}-\mathrm{CH}_{2}-$ or $-\mathrm{CH}_{2}-\mathrm{O}-\mathrm{CH}_{2}-$ ). These bridge aromatic systems can undergo intramolecular $[4+4]$ photocycloadditions to form "biplanemers," in which the two $\pi$ systems are stacked face-to-face [19].

To date, the mechanism of cycloaddition among aromatic ring compounds has not been clearly characterized. 
Rogachev and coworkers [20] performed a series of calculations involving benzene dimers in the ground state, but no studies have been made on the photochemical dimerization of benzene. In this paper, we studied photoinduced [2+ 2] cycloaddition of two-benzene system by semiclassical dynamic simulation. The simulation results provide detailed dynamics features for this process from photon excitation to the formation of product. The geometry at the conical intersection (CI) between the first singlet $\left(S_{1}\right)$ excited state and ground state $\left(S_{0}\right)$ was optimized by using completed active space self-consistent field (CASSCF) method to compare with other theoretical results.

\section{Methodology}

2.1. Semiclassical Dynamics Simulation. We carried out the dynamics simulations using the semiclassical electronradiation-ion dynamics (SERID) method. In this approach, the valence electrons are calculated by the time-dependent Schrödinger equation while both the radiation field and the motion of the nuclei are treated by the classical approximation. A detailed description of this technique has been published elsewhere [21,22] and only a brief review is given here. The one-electron states are updated by solving the time-dependent Schrödinger equation at each time step (typically 0.05 femtoseconds in duration) in a nonorthogonal basis,

$$
i \hbar \frac{\partial \Psi_{j}}{\partial t}=\mathbf{S}^{-1} \cdot \mathbf{H} \cdot \Psi_{j},
$$

where $\mathbf{S}$ is the overlap matrix for the atomic orbitals. The laser pulse is characterized by the vector potential $\mathbf{A}$, which is coupled to the Hamiltonian via the time-dependent Peierls substitution

$$
H_{a b}\left(\mathbf{X}-\mathbf{X}^{\prime}\right)=H_{a b}^{0}\left(\mathbf{X}-\mathbf{X}^{\prime}\right) \exp \left(\frac{i q}{\hbar c} \mathbf{A} \cdot\left(\mathbf{X}-\mathbf{X}^{\prime}\right)\right)
$$

here $H_{a b}\left(\mathbf{X}-\mathbf{X}^{\prime}\right)$ is the Hamiltonian matrix element for basis functions $a$ and $b$ on atoms at $\mathbf{X}$ and $\mathbf{X}^{\prime}$, respectively, and $q=$ $-e$ is the charge of the electron.

The Hamiltonian matrix elements, overlap matrix elements, and repulsive energy are calculated with the densityfunctional based tight bonding (DFTB) method. The DFTB method does have essentially the same strengths and limitations as time-dependent density-functional theory (TDDFT). In particularly, the bonding is well described but the excited state energies are typically too low. For this reason, we matched the effective central photon energy of the laser pulse to the relevant density-functional (rather than experimental) excitation energy and this should not adversely affect the interpretation of the results. This model has been used in biologically relevant studies such as photoinduced dimerization of thymine [23] and cytosine [24] via [2+2] photocycloaddition reaction. All the results were found to be consistent with experimental observations. The formation of cyclobutane pyrimidine dimer may provide good references for $[2+2]$ photocycloaddition of benzene.
In this technique, forces acting on nucleus or ions are computed by the Ehrenfest equation

$$
\begin{aligned}
& M_{l} \frac{d^{2} X_{l \alpha}}{d t^{2}} \\
& \quad=-\frac{1}{2} \sum_{j} \Psi_{j}^{+} \cdot\left(\frac{\partial \mathbf{H}}{\partial X_{l \alpha}}-i \hbar \frac{1}{2} \frac{\partial \mathbf{S}}{\partial X_{l \alpha}} \cdot \frac{\partial}{\partial t}\right) \cdot \Psi_{j}-\frac{\partial U_{\text {rep }}}{\partial X_{l \alpha}},
\end{aligned}
$$

where $U_{\text {rep }}$ is effective nuclear-nuclear repulsive potential and $X_{l \alpha}=\left\langle\widehat{X}_{l \alpha}\right\rangle$ is the expectation value of the time-dependent Heisenberg operator for the $\alpha$ coordinate of the nucleus labeled by $l$ (with $\alpha=x, y, z$ ). Equation (3) is obtained by neglecting the second and higher order terms of the quantum fluctuations $\widehat{X}-\left\langle\widehat{X}_{l \alpha}\right\rangle$ in the exact Ehrenfest theorem.

The present "Ehrenfest" principle is complementary to other methods based on different approximations, such as the full multiple spawning model developed by the BenNun and Martínez [25]. The limitation of this method is that the simulation trajectory moves along a path dominated by averaging over all the terms in the Born-Oppenheimer expansion $[26,27]$,

$$
\Psi^{\text {total }}\left(X_{n}, x_{e}, t\right)=\sum_{i} \Psi_{i}^{n}\left(X_{n}, t\right) \Psi_{i}^{e}\left(x_{e}, X_{n}\right),
$$

rather than following the time evolution of a single potential energy surface, which is approximately decoupled from all the others [26-29]. (Here $X_{n}$ and $x_{e}$ represent the sets of nuclear and electronic coordinates resp., and the $\Psi_{i}^{e}$ are eigenstates of the electronic Hamiltonian at fixed $X_{n}$.) The strengths of the present approach include retention of all of the $3 \mathrm{~N}$ nuclear degrees of freedom and the incorporation of the laser excitation as well as the subsequent deexcitation at an avoided crossing near a conical intersection.

2.2. CASSCF. Multiconfigurational self-consistent field (MCSCF) is a method in quantum chemistry used to generate qualitatively correct reference states of molecules in cases where Hartree-Fock (HF) and DFT are not adequate (e.g., for molecular ground states which are quasidegenerate with low lying excited states or in bond breaking situations). It uses a linear combination of configuration state functions (CSF) or configuration determinants to approximate the exact electronic wavefunction of an atom or molecule. In an MCSCF calculation, the set of coefficients of both the CSFs or determinants and the basis functions in the molecular orbitals are varied to obtain the total electronic wavefunction with the lowest possible energy. This method can be considered a combination of configuration interaction (where the molecular orbitals are not varied but the expansion of the wave function are varied) and Hartree-Fock (where there is only one determinant but the molecular orbitals are varied). A particularly important MCSCF approach is the CASSCF, where the linear combination of CSFs includes all that arise from a particular number of electrons in a particular number of orbitals [30, 31].

In this research, the CASSCF $a b$ initio computations used a 12-electron and 12-orbital active space involving all 


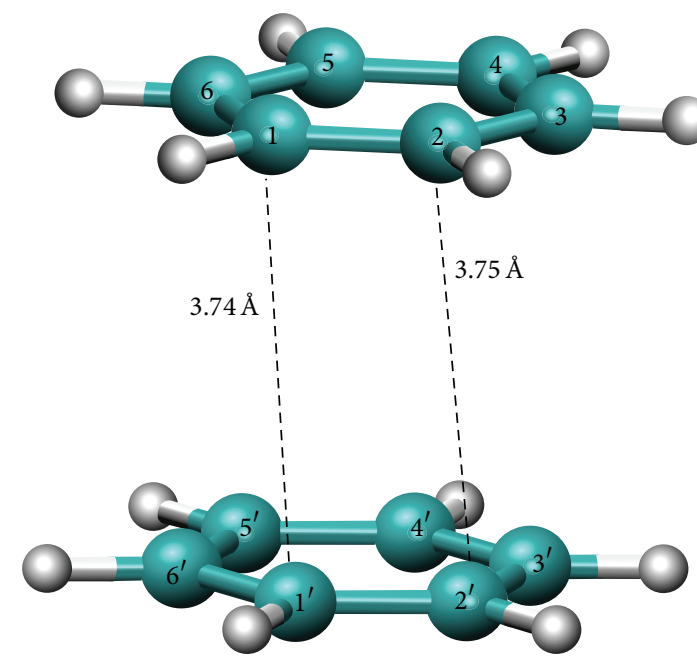

(a)

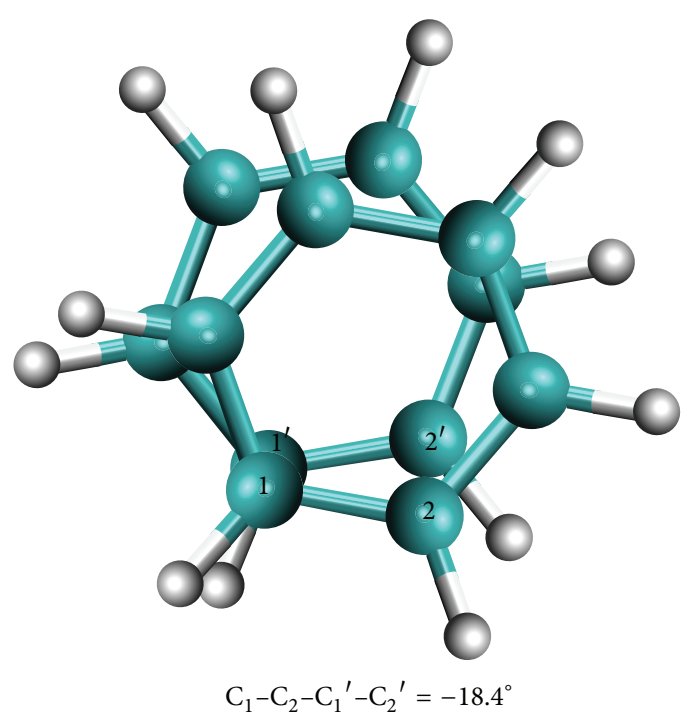

(b)

Figure 1: Conformation and atomic labeling for the stacked benzene system.

the $\pi$-orbitals of two benzene moieties. All the geometries were optimized using the 6-31G(d) basis set in Gaussian09 software package [32]. To enhance calculation efficiency, the geometry at the decay time in simulation trajectory was picked as the initial guess for CI optimization.

\section{Results and Discussions}

From the reported experiments and ab initio calculations [3337], the ground state of two stacked benzenes can have two nearly isoenergetic stable structures (T-shaped and slippedparallel) and a less stable sandwich structure. Electrostatic interaction stabilizes the T-shaped structure, while dispersion stabilizes the slipped-parallel structure. The initial structure used in our calculations, shown in Figure 1, is slipped parallel. Primed and unprimed labels are used to differentiate atoms in the two molecules. We fixed the $\mathrm{C}_{1}-\mathrm{C}_{1}{ }^{\prime}$ and $\mathrm{C}_{2}-\mathrm{C}_{2}{ }^{\prime}$ distances based on the geometries of [2+2] cycloaddition of hexatomic pyrimidine base $[23,24]$.

To obtain ground state equilibrium configurations of two benzene-system, the simulation was run at room temperature for $1000 \mathrm{fs}$, an "equilibrated" geometry was taken at twenty equal time intervals over the $1000 \mathrm{fs}$ time period, and each one was excited with the laser pulse to generate the trajectories. A 25 fs FWHM laser pulse with a Gaussian profile, and $4.7 \mathrm{eV}$ photon energy, was applied to the top benzene molecule. The selected photon energy matches the calculated HOMO-LUMO energy gap. A fluence between 10 and $50 \mathrm{~J} / \mathrm{m}^{2}$ was randomly chosen for this study. This fluence results in an electronic excitation but the forces produced do not break any bonds. The same laser pulse (Case 1: $40.49 \mathrm{~J} / \mathrm{m}^{2}$ fluence; Case 2: $43.26 \mathrm{~J} / \mathrm{m}^{2}$ fluence) is used for all 20 trajectories; one representative trajectory is reported in this paper. The other trajectories have similar results with the representative one.

Figure 2 shows the HOMO-1, HOMO, LUMO, and $\mathrm{LUMO}+1$ for the equilibrated structure computed by the
DFTB approximation. Based on Woodward-Hoffmann rules, the formation of cyclobutane benzene dimer is a symmetryforbidden reaction when both molecules are at the electronic ground states or have one electron promoted from the HOMO to the LUMO. However, the reaction is symmetryallowed when one molecule is at electronic ground state and another one has one electron excited from the HOMO to the LUMO. These are evident from the molecular orbital diagram.

Case 1. Formation of cyclobutane benzene dimer.

In this section, we present and discuss the simulation results for the formation of cyclobutane benzene dimer. Six snapshots taken from the simulation at different times are shown in Figure 3. Figure 3(a) represents electronic excitation of the top molecule in the equilibrated geometry at $0 \mathrm{fs}$. The excited molecule is distorted (Figure 3(b)) and moves toward the unexcited molecule (Figure 3(c)). The unexcited molecule is deformed due to the approach of the excited molecule (Figure 3(d)). At $770 \mathrm{fs}, \mathrm{C}_{1}-\mathrm{C}_{1}{ }^{\prime}$ bond has been formed (Figure $3(\mathrm{e})$ ). The second bond, $\mathrm{C}_{2}-\mathrm{C}_{2}{ }^{\prime}$, is formed at $1000 \mathrm{fs}$ (Figure 3(f)). The structure of cyclobutane benzene remains stable by the end of the simulation.

The variations with time of the lengths of the $\mathrm{C}_{1}-\mathrm{C}_{2}$ and $\mathrm{C}_{1}{ }^{\prime}-\mathrm{C}_{2}{ }^{\prime}$ bonds and the distances of $\mathrm{C}_{1}-\mathrm{C}_{1}{ }^{\prime}$ and $\mathrm{C}_{2}-\mathrm{C}_{2}{ }^{\prime}$ are presented in Figure 4 . Both $\mathrm{C}_{1}-\mathrm{C}_{2}$ and $\mathrm{C}_{1}{ }^{\prime}-\mathrm{C}_{2}{ }^{\prime}$ bonds are double bonds in the benzene molecules but become single bonds in the benzene dimer. The $\mathrm{C}_{1}-\mathrm{C}_{2}$ bond length starts at about $1.4 \AA$, typical for a $\mathrm{C}=\mathrm{C}$ double bond in an arene, and then lengthens after the laser pulse is applied. The excited benzene molecule approaches the unexcited benzene molecule and influences its structure, as shown by the increase in the $\mathrm{C}_{1}{ }^{\prime}-\mathrm{C}_{2}{ }^{\prime}$ bond length after $200 \mathrm{fs}$. Both bond lengths increase to about $1.5 \AA$ after $600 \mathrm{fs}$, because of the formation of the cyclobutane benzene dimer, and they remain at this length until the end of the simulation. Both 

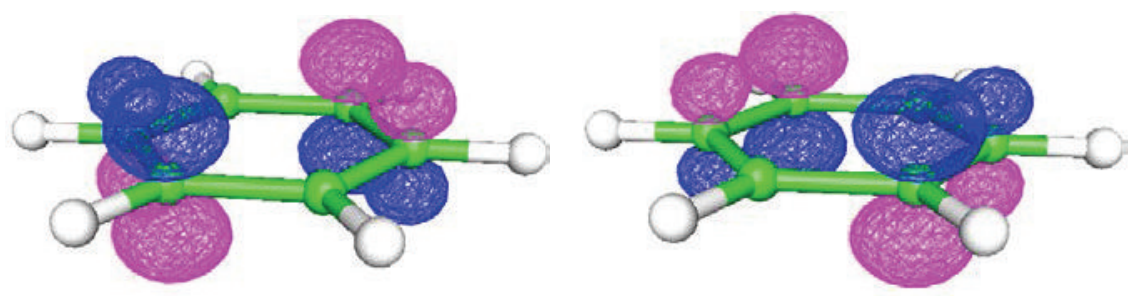

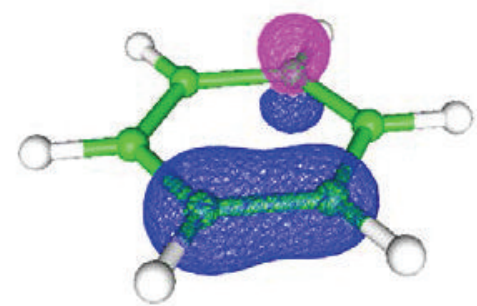

(a)

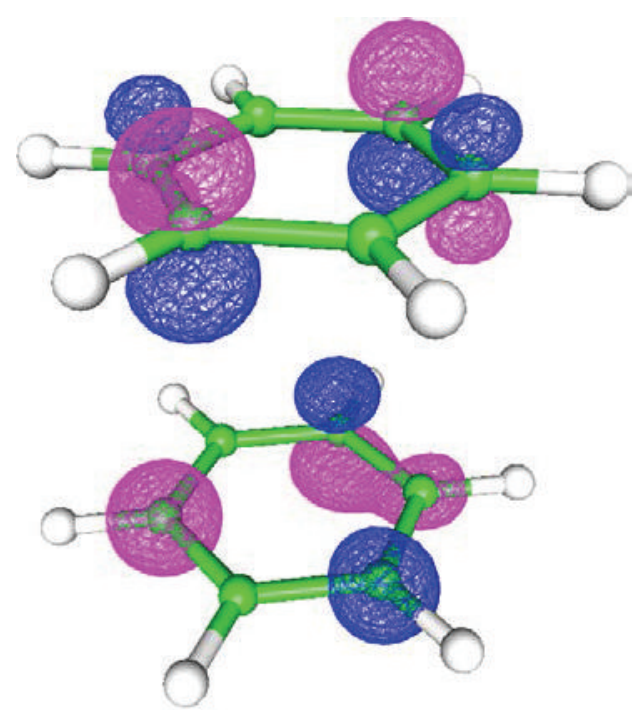

(c)

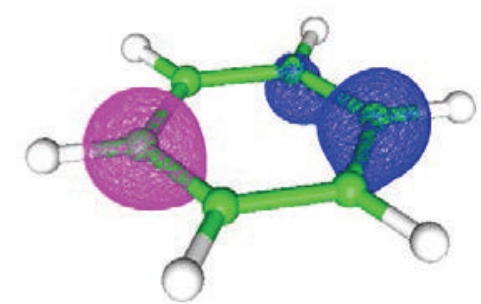

(b)

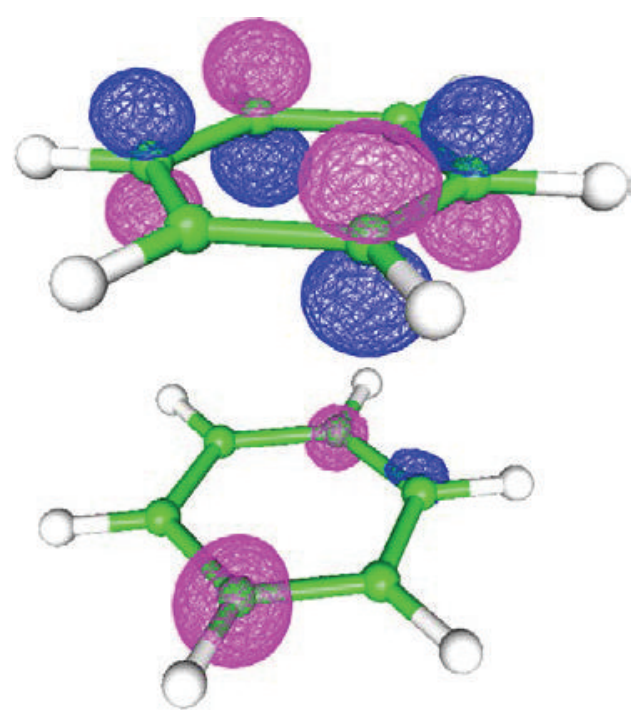

(d)

Figure 2: The diagrams of the (a) HOMO-1 (b), HOMO, (c) LUMO, and (d) LUMO + 1 of two stacked benzene molecules at the equilibrated geometry.

distances roughly remain at their initial values by $200 \mathrm{fs}$ and start to decrease thereafter. The $\mathrm{C}_{1}-\mathrm{C}_{1}{ }^{\prime}$ distance decreases to below $1.5 \AA$ at about $770 \mathrm{fs}$. The $\mathrm{C}_{2}-\mathrm{C}_{2}{ }^{\prime}$ distance drops to about $2.1 \AA$ at about $830 \mathrm{fs}$, retains this value for $170 \mathrm{fs}$, and then drops to about $1.5 \AA$ at about $1000 \mathrm{fs}$. This is the time for the formation of the cyclobutane benzene dimer.

The variations with time of the HOMO-1, HOMO, LUMO, and LUMO+1 energies are shown in Figure 5 along with the time-dependent population of the orbitals. Note that the HOMO and HOMO-1 are initially two identical HOMOs of the benzene monomer molecules and the LUMO and LUMO+1 are initially two identical LUMOs of the two molecules before laser excitation. Figure 5(a) shows that there is an abrupt change in the LUMO energy soon after application of the laser pulse. The HOMO and LUMO levels find one close approach, with avoided crossings, with the energy gaps being $0.04 \mathrm{eV}$ at $770 \mathrm{fs}$. Figure 5(b) shows that by the end of the laser pulse (which is $50 \mathrm{fs}$ ) about 1 electron is excited from the HOMO to the LUMO, consistent with the promotion of one benzene molecule to an electronically excited state. The coupling between the HOMO and LUMO, as observed in Figure 5(a), leads to notable electronic transitions from the LUMO to the HOMO. This deexcitation eventually brings the molecule to the electronic ground state. It can be seen from Figure 6 that shortly after the coupling both the LUMO and HOMO levels move toward their initial values. After $1000 \mathrm{fs}$, when the formation of the cyclobutane benzene dimer is completed, these two energy levels only show fluctuations about constants values, which are essentially the same as their initial values. On the other hand, the LUMO+1 and HOMO-1 levels only show slight variations during the reaction, since they are the LUMO and HOMO of the unexcited molecule, respectively.

Case 2. Formation and subsequent cleavage of only one $\sigma$ bond between the two benzene molecules. 

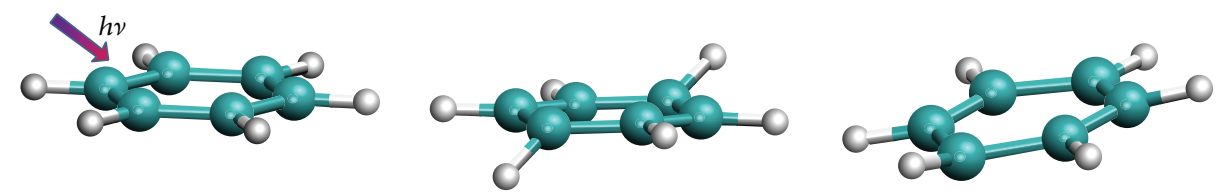

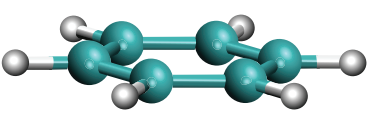

(a)

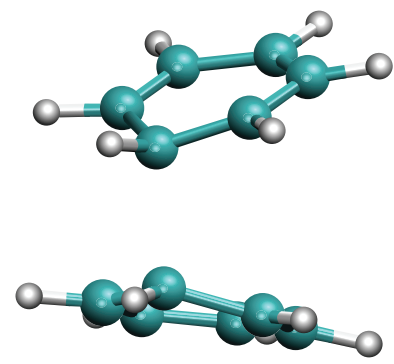

(d)

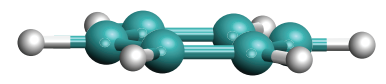

(b)

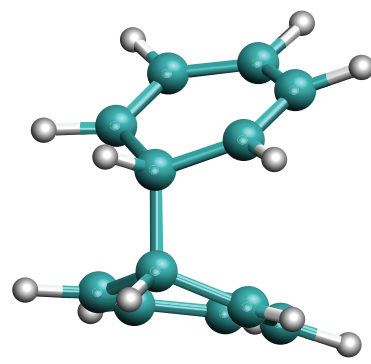

(e)

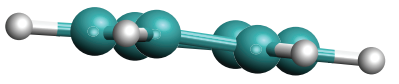

(c)

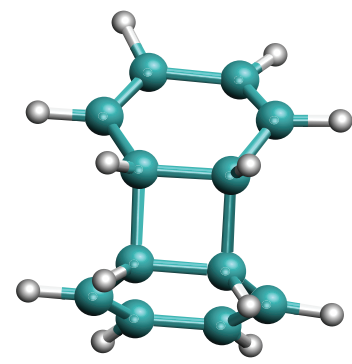

(f)

FIGURE 3: Snapshots taken from the simulation of two stacked benzene molecules at (a) 0, (b) 300, (c) 700, (d) 740, (e) 770, and (f) 1000 fs. The molecule at the top is subjected to the irradiation of a $25 \mathrm{fs}\left(\mathrm{fwhm}\right.$ ) laser pulse with a fluence of $40.49 \mathrm{~J} \cdot \mathrm{m}^{-2}$ and photon energy of $4.7 \mathrm{eV}$. This trajectory leads to the formation of cyclobutane benzene dimer and is briefly defined as Case 1 .

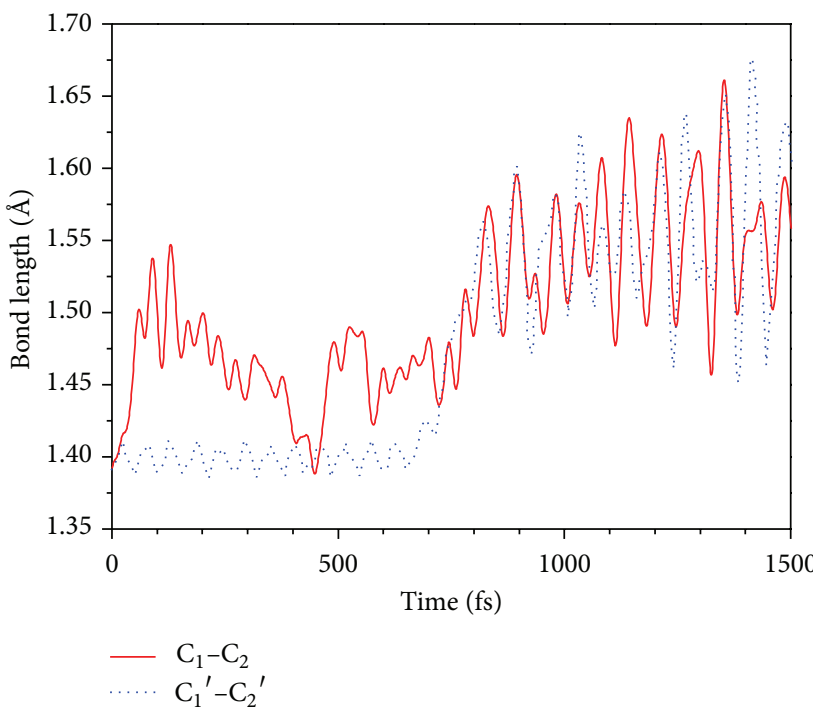

(a)

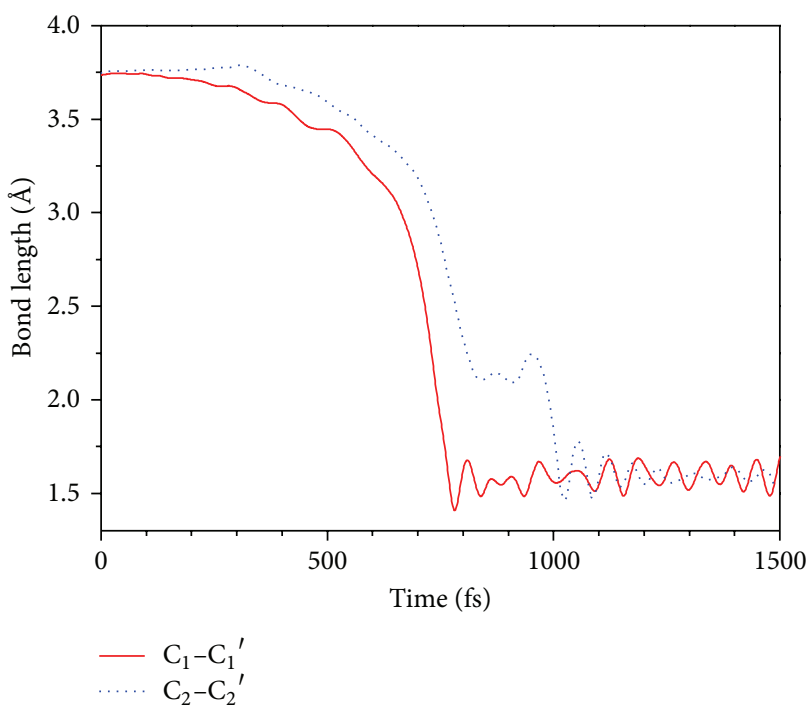

(b)

Figure 4: The variations with time of (a) $\mathrm{C}_{1}-\mathrm{C}_{2}$ and $\mathrm{C}_{1}{ }^{\prime}-\mathrm{C}_{2}{ }^{\prime}$ bond lengths and (b) the lengths between the $\mathrm{C}_{1}$ and $\mathrm{C}_{2}$ atoms and the $\mathrm{C}_{1}{ }^{\prime}$ and $\mathrm{C}_{2}{ }^{\prime}$ atoms in two stacked benzene molecules in Case 1.

The simulation results presented in this section show that under the laser irradiation two molecules form a $\sigma$ bond between the $\mathrm{C}_{1}$ and $\mathrm{C}_{1}{ }^{\prime}$ atom sites. However, this $\sigma$ bond only has a lifetime of several ten femtoseconds and breaks shortly after it is formed.

Six snapshots taken from the simulation at different times are shown in Figure 6. One finds that at $930 \mathrm{fs}$ two molecules have already formed a chemical bond between the $\mathrm{C}_{1}$ and
$\mathrm{C}_{1}{ }^{\prime}$ atoms (Figure 6(d)) but the bond breaks shortly thereafter and the two molecules move away from each other (Figures $6(\mathrm{e})$ and $6(\mathrm{f}))$.

The variations with time of the $\mathrm{C}_{1}-\mathrm{C}_{2}$ and $\mathrm{C}_{1}{ }^{\prime}-\mathrm{C}_{2}{ }^{\prime}$ bond lengths are plotted in Figure $7(\mathrm{a})$. The $\mathrm{C}_{1}-\mathrm{C}_{2}$ bond stretches in length soon after the laser pulse is applied due to the excitation of electrons from the HOMO to LUMO and shrinks to its original length shortly after $900 \mathrm{fs}$ when the 


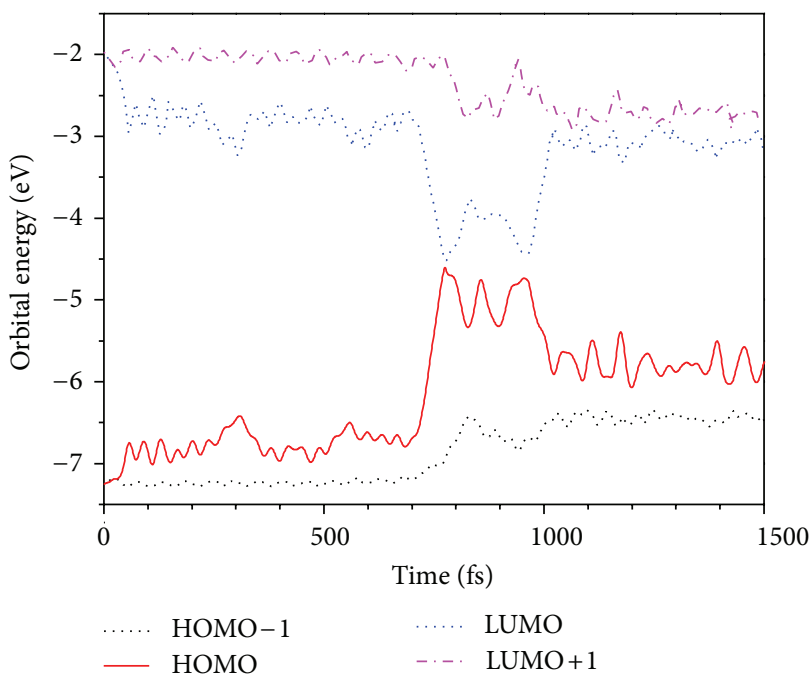

(a)

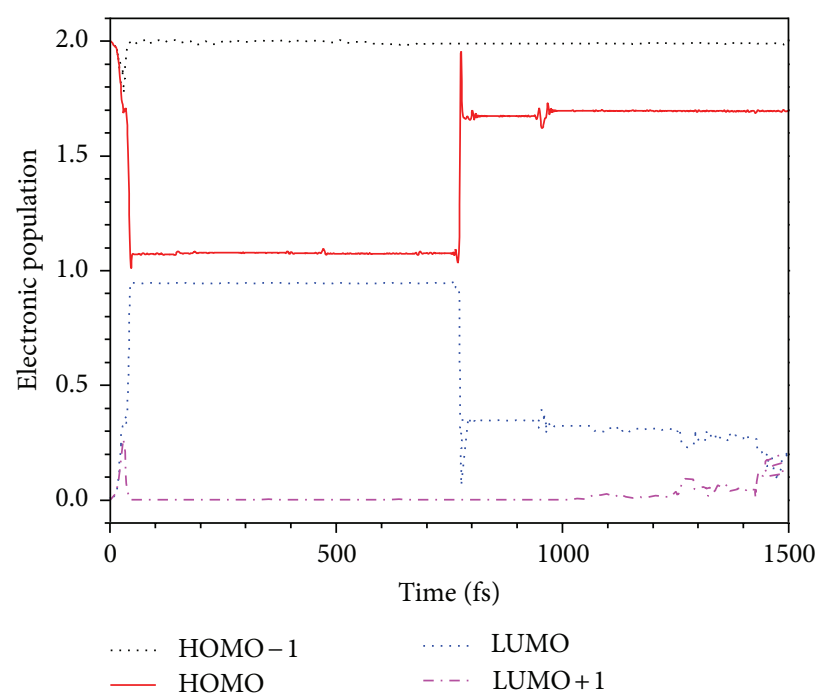

(b)

FIGURE 5: The variations with time of (a) orbital energies and (b) time-dependent populations of the HOMO-1, HOMO, LUMO, and LUMO+1 of two benzene molecules in Case 1.
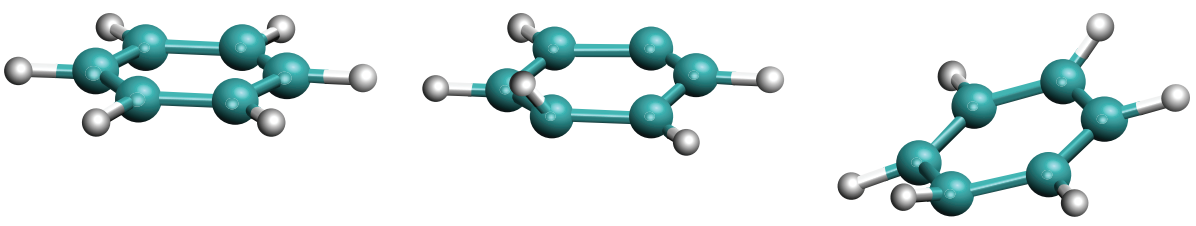

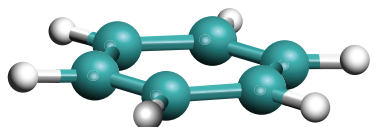

(a)

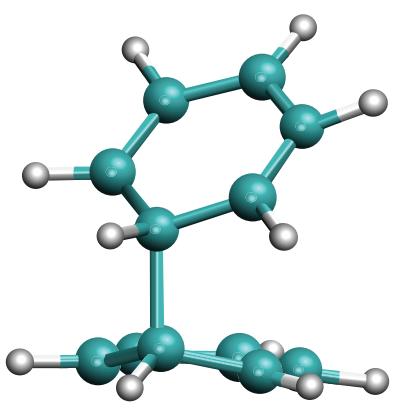

(d)

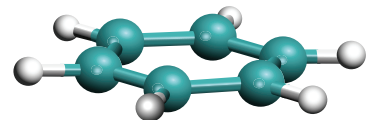

(b)

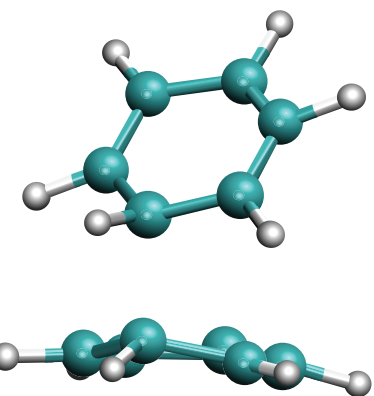

(e)

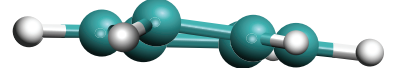

(c)

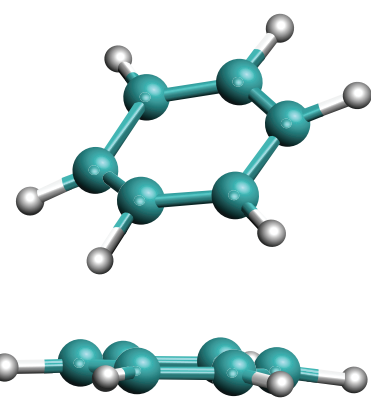

(f)

FIGURE 6: Snapshots taken from the simulation of two stacked benzene molecules at (a) 0, (b) 350, (c) 790, (d) 930, (e) 960, and (f) 1100 fs. The molecule at the top is subjected to the irradiation of a $25 \mathrm{fs}$ (fwhm) laser pulse with a fluence of $43.26 \mathrm{~J} \cdot \mathrm{m}^{-2}$ and photon energy of $4.7 \mathrm{eV}$. This trajectory results in the breaking of $\mathrm{C}_{1}-\mathrm{C}_{1}{ }^{\prime}$ bond and is briefly defined as Case 2 .

bond linking two benzene molecules is broken. However, the $\mathrm{C}_{1}{ }^{\prime}-\mathrm{C}_{2}{ }^{\prime}$ bond shows little variation since excitation. A sharp jump up and down in the $\mathrm{C}_{1}{ }^{\prime}-\mathrm{C}_{2}{ }^{\prime}$ bond length during 900 to $1000 \mathrm{fs}$ indicates the formation and breakage of the bond between two benzene molecules. The variations with time of the $\mathrm{C}_{1}-\mathrm{C}_{1}{ }^{\prime}$ and $\mathrm{C}_{2}-\mathrm{C}_{2}{ }^{\prime}$ distances are plotted in Figure $7(\mathrm{~b})$ for this process. Both distances do not exhibit significant changes until $400 \mathrm{fs}$ but show a decrease afterwards due to the interaction between two close molecules. The $\mathrm{C}_{1}-\mathrm{C}_{1}{ }^{\prime}$ distance becomes about $1.5 \AA$ at about $930 \mathrm{fs}$, indicating the formation of a $\mathrm{C}-\mathrm{C} \sigma$-bond. Immediately after that, the distances between the $\mathrm{C}_{1}$ and $\mathrm{C}_{1}{ }^{\prime}$ atoms and the $\mathrm{C}_{2}$ and $\mathrm{C}_{2}{ }^{\prime}$ atoms increase quickly because two molecules separated from each other. 


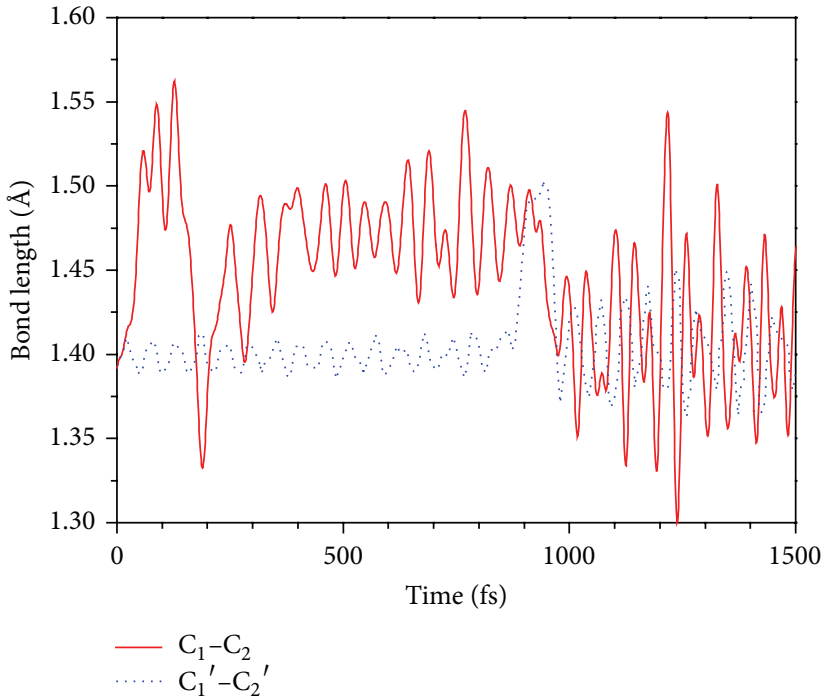

(a)

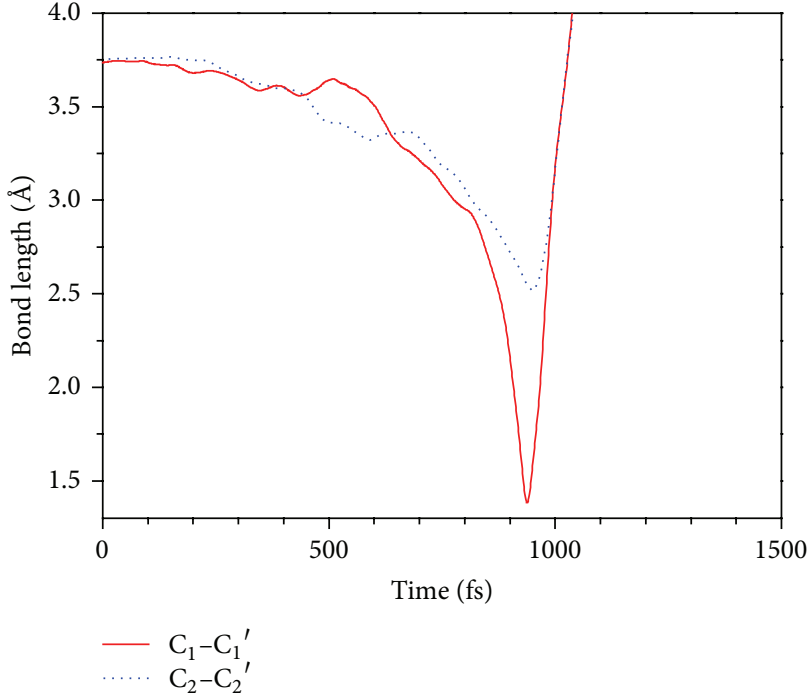

(b)

Figure 7: The variations with time of (a) $\mathrm{C}_{1}-\mathrm{C}_{2}$ and $\mathrm{C}_{1}{ }^{\prime}-\mathrm{C}_{2}{ }^{\prime}$ bond lengths and (b) the lengths between the $\mathrm{C}_{1}$ and $\mathrm{C}_{2}$ atoms and the $\mathrm{C}_{1}{ }^{\prime}$ and $\mathrm{C}_{2}{ }^{\prime}$ atoms in two stacked benzene molecules in Case 2.

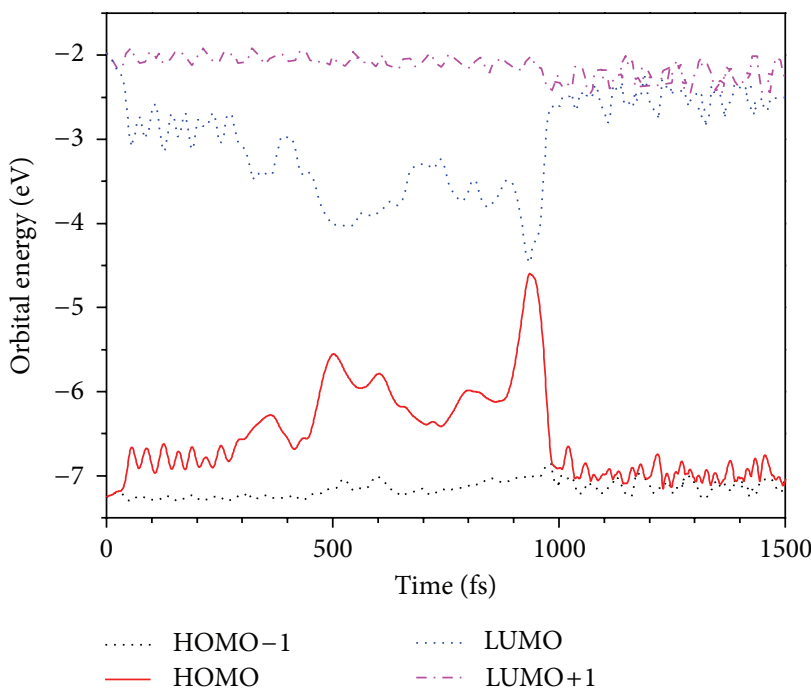

(a)

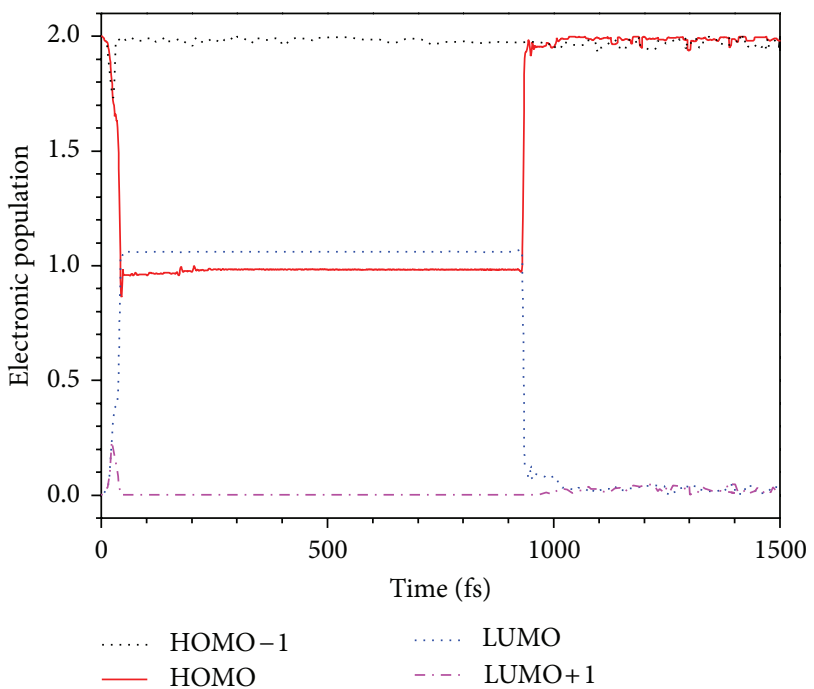

(b)

FIGURE 8: The variations with time of (a) orbital energies and (b) time-dependent populations of the HOMO-1, HOMO, LUMO, and LUMO+1 of two benzene molecules in Case 2 .

The variations of the HOMO-1, HOMO, LUMO, and LUMO+1 energies as a function of time are shown in Figure $8(\mathrm{a})$ and the time-dependent populations of the HOMO and LUMO are shown in Figure 8(b). An avoided crossing between the HOMO and LUMO levels is found with the energy gaps being $0.05 \mathrm{eV}$ at $605 \mathrm{fs}$. This avoided crossing leads to notable electronic transition from the LUMO to HOMO, which eventually directs the excimer to the electronic ground state.

3.1. Discussion. It is seen from Figures $4,5,7$, and 8 that the formation of the $\mathrm{C}_{1}-\mathrm{C}_{1}{ }^{\prime}$ and $\mathrm{C}_{2}-\mathrm{C}_{2}{ }^{\prime}$ bonds has a crucial impact on the nonadiabatic transition of the excimer to the electronic ground state. In addition, the deformation of the benzene ring, especially the deformation of the benzene rings at $\mathrm{C}_{1}, \mathrm{C}_{2}, \mathrm{C}_{1}{ }^{\prime}$, and $\mathrm{C}_{2}{ }^{\prime}$ atoms sites, also has a notable influence on the nonadiabatic transition of the excimer to ground state. To understand this, a comparison between the $\mathrm{C}_{5}-\mathrm{C}_{6}-\mathrm{C}_{1}-$ $\mathrm{C}_{2}$ and $\mathrm{C}_{5}{ }^{\prime}-\mathrm{C}_{6}{ }^{\prime}-\mathrm{C}_{1}{ }^{\prime}-\mathrm{C}_{2}{ }^{\prime}$ dihedral angles and the energy gap between the HOMO and LUMO for each case is plotted in Figure 9. The deformation of the benzene ring at the $C_{1}, C_{2}$, $\mathrm{C}_{1}{ }^{\prime}$, and $\mathrm{C}_{2}{ }^{\prime}$ atoms sites is represented by these two dihedral angles. It is seen that, for each case, the minimum of the energy gap is in line with a sharp rise of the $\mathrm{C}_{5}{ }^{\prime}-\mathrm{C}_{6}{ }^{\prime}-\mathrm{C}_{1}{ }^{\prime}-\mathrm{C}_{2}{ }^{\prime}$ 


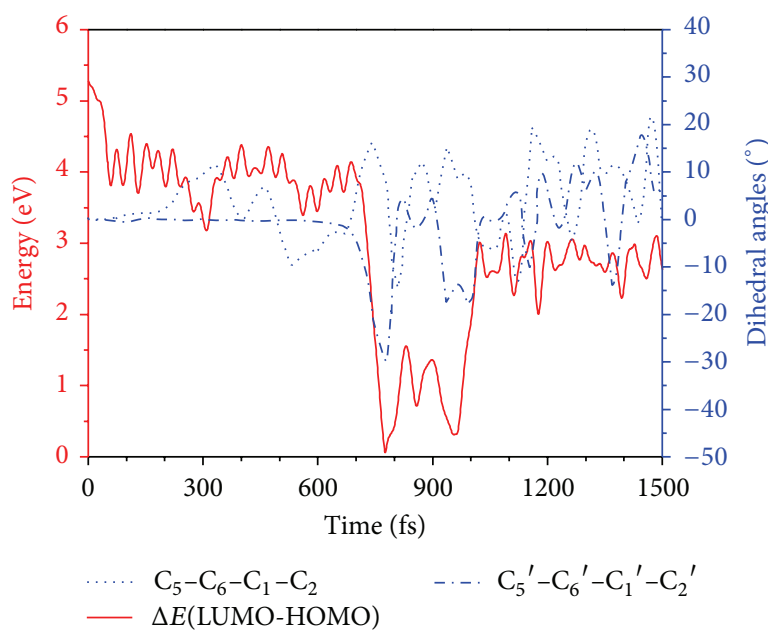

(a)

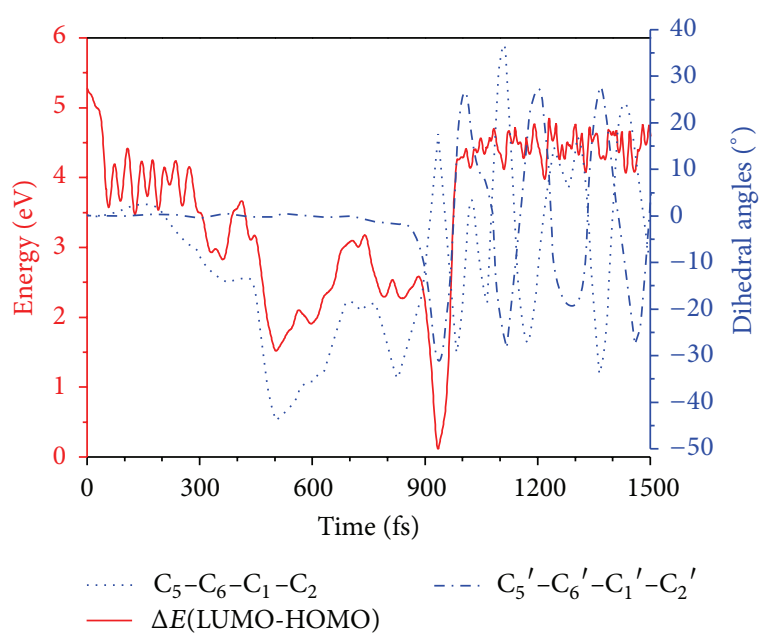

(b)

Figure 9: Comparison between the $\mathrm{C}_{5}-\mathrm{C}_{6}-\mathrm{C}_{1}-\mathrm{C}_{2}$ and $\mathrm{C}_{5}{ }^{\prime}-\mathrm{C}_{6}{ }^{\prime}-\mathrm{C}_{1}{ }^{\prime}-\mathrm{C}_{2}{ }^{\prime}$ dihedral angles and the energy gap between the $\mathrm{HOMO}$ and LUMO of two stacked benzene molecules: (a) Case 1 and (b) Case 2.

dihedral angle and a sharp dip in the $\mathrm{C}_{5}-\mathrm{C}_{6}-\mathrm{C}_{1}-\mathrm{C}_{2}$ dihedral angle, suggesting that in both cases the deformation of the benzene ring plays an important role in the nonadiabatic transition of the excimer to ground state.

In Case 2 the $\mathrm{C}_{1}-\mathrm{C}_{1}{ }^{\prime}$ bond between two benzenes is broken about $50 \mathrm{fs}$ after its formation. To understand how the structural deformation of the benzene ring impacts the cleavage of the $\mathrm{C}_{1}-\mathrm{C}_{1}{ }^{\prime}$ bond, it is worthwhile to the compare the distances between the $\mathrm{C}_{1}$ and $\mathrm{C}_{1}{ }^{\prime}$ atoms and the $\mathrm{C}_{2}$ and $\mathrm{C}_{2}{ }^{\prime}$ atoms and the $\mathrm{C}_{5}-\mathrm{C}_{6}-\mathrm{C}_{1}-\mathrm{C}_{2}$ and $\mathrm{C}_{5}{ }^{\prime}-\mathrm{C}_{6}{ }^{\prime}-\mathrm{C}_{1}{ }^{\prime}-\mathrm{C}_{2}{ }^{\prime}$ dihedral angles. For the formation of the cyclobutane benzene dimer, the dihedral angle of $\mathrm{C}_{5}{ }^{\prime}-\mathrm{C}_{6}{ }^{\prime}-\mathrm{C}_{1}{ }^{\prime}-\mathrm{C}_{2}{ }^{\prime}$ is almost constant before $680 \mathrm{fs}$ (i.e., just before the formation of the $\mathrm{C}_{1}-\mathrm{C}_{1}{ }^{\prime}$ bond) and then quickly decreases to $-30^{\circ}$. After that, this dihedral angle fluctuates around its initial value until the end of simulation. On the other hand, the dihedral angle of $\mathrm{C}_{5}-\mathrm{C}_{6}-\mathrm{C}_{1}-\mathrm{C}_{2}$ has a relatively smaller change in amplitude. In particular, during 770 to $1050 \mathrm{fs}$, in which the $\mathrm{C}_{1}-\mathrm{C}_{1}{ }^{\prime}$ bond is formed and $\mathrm{C}_{2}-\mathrm{C}_{2}{ }^{\prime}$ is not bonding, the value of $\mathrm{C}_{5}-\mathrm{C}_{6}-\mathrm{C}_{1}-\mathrm{C}_{2}$ dihedral angle is dominantly positive. This suggests movement of $\mathrm{C}_{1}$ and $\mathrm{C}_{2}$ towards the bottom molecule, enhancing the likelihood of $\mathrm{C}_{2}-\mathrm{C}_{2}{ }^{\prime}$ bonding. For Case 2, however, the $\mathrm{C}_{5}-\mathrm{C}_{6}-\mathrm{C}_{1}-\mathrm{C}_{2}$ dihedral angle oscillates between $-30^{\circ}$ and $30^{\circ}$ after formation of the $\mathrm{C}_{1}-\mathrm{C}_{1}{ }^{\prime}$ bond. This strong vibration deters the formation of a bond between the $\mathrm{C}_{2}$ and $\mathrm{C}_{2}{ }^{\prime}$ and also makes the $\mathrm{C}_{1}-\mathrm{C}_{1}{ }^{\prime}$ bond unstable. We therefore conclude that the forces produced by the deformation of the benzene ring at $C_{1}$ site break the $C_{1}-C_{1}{ }^{\prime}$ bond and prevent the formation of the cyclobutane benzene dimer.

The time evolution of the net charge of the excited benzene molecule (benzene 1) in Cases 1 and 2 is shown in Figures $10(\mathrm{a})$ and $10(\mathrm{c})$, respectively. Figure $10(\mathrm{~b})$ is an expanded view of Figure 10(a) from 600 to $1100 \mathrm{fs}$, with $\mathrm{C}_{1}-\mathrm{C}_{1}{ }^{\prime}$ and $\mathrm{C}_{2}-\mathrm{C}_{2}{ }^{\prime}$ distances shown for comparison. Figure 10(d) is an expanded view of Figure 10(c) from 800 to $1000 \mathrm{fs}$, with $\mathrm{C}_{1}-\mathrm{C}_{1}{ }^{\prime}$ and $\mathrm{C}_{2}-\mathrm{C}_{2}{ }^{\prime}$ distances also shown for comparison. For the formation of the cyclobutane benzene dimer (Case 1), although electrons hop frequently between the two benzene molecules from 700 to $1000 \mathrm{fs}$, it can be hardly defined as "charge transfer state" overall. Only at $770 \mathrm{fs}$, when the avoided crossing occurs, a zwitterion is clearly formed. However, the excited benzene molecule almost immediately returns to electric neutrality. In the zwitterionic geometry, $\mathrm{C}_{1}$ and $\mathrm{C}_{1}{ }^{\prime}$ atoms are linked by a $\sigma$ chemical bond with length of $1.58 \AA$, while the $\mathrm{C}_{2}$ and $\mathrm{C}_{2}{ }^{\prime}$ distance is $2.66 \AA$. A "bonded-intermediate" is almost immediately formed as the $\mathrm{C}_{2}-\mathrm{C}_{2}{ }^{\prime}$ distance shortens from 2.6 to about $2.1 \AA$. After $1000 \mathrm{fs}$, the bonded-intermediate has converted into the cyclobutane benzene dimer because of $\mathrm{C}_{2}-\mathrm{C}_{2}{ }^{\prime}$ bonding. In Case 2, as shown in Figures $10(\mathrm{c})$ and $10(\mathrm{~d})$, the zwitterionic exists for about $20 \mathrm{fs}$ and then $\mathrm{C}_{1}-\mathrm{C}_{1}{ }^{\prime}$ bond is broken. The bonded-intermediate is not observed in Case 2.

The molecular geometry at the avoided crossing of both cases is shown in Figure 11 with a few critical geometry parameters indicated. The distances of $\mathrm{C}_{1}-\mathrm{C}_{1}{ }^{\prime}$ and $\mathrm{C}_{2}-\mathrm{C}_{2}{ }^{\prime}$ of Case 1 are 1.58 and $2.66 \AA$, respectively. The interatomic distances of Case 2 are 1.57 and $2.61 \AA$, respectively. Figures $11(\mathrm{a})$ and $11(\mathrm{~b})$ are not significantly different. It suggests that the electronic decay point, which is bonded-intermediate structure, may lead to either $[2+2]$ photoaddition product or reversal, depending on the vibrations of $\mathrm{C}_{1}, \mathrm{C}_{2}, \mathrm{C}_{1}{ }^{1}$, and $\mathrm{C}_{2}{ }^{\prime}$ atoms.

The interatomic distances of $\mathrm{C}_{1}-\mathrm{C}_{1}{ }^{\prime}$ and $\mathrm{C}_{2}-\mathrm{C}_{2}{ }^{\prime}$ are $1.64 \AA$ and $2.60 \AA$, respectively, (as seen in Figure 12) by using CASSCF optimization for the $S_{1} / S_{0}$ CI of two-benzene system. It is worth noting that the $\mathrm{C}_{3}-\mathrm{C}_{2}{ }^{\prime}$ distance in the CI geometry is only $2.21 \AA$, which is far less than that obtained in our semiclassical dynamics simulations (both Cases 1 and 2). This CASSCF geometry is very similar to the CI of benzene and ethylene system calculated by Clifford and coworkers [13]. Decay from this CI point may lead to either $[2+2]$, $[2+3]$, or $[2+4]$ photoaddition product, although formation 


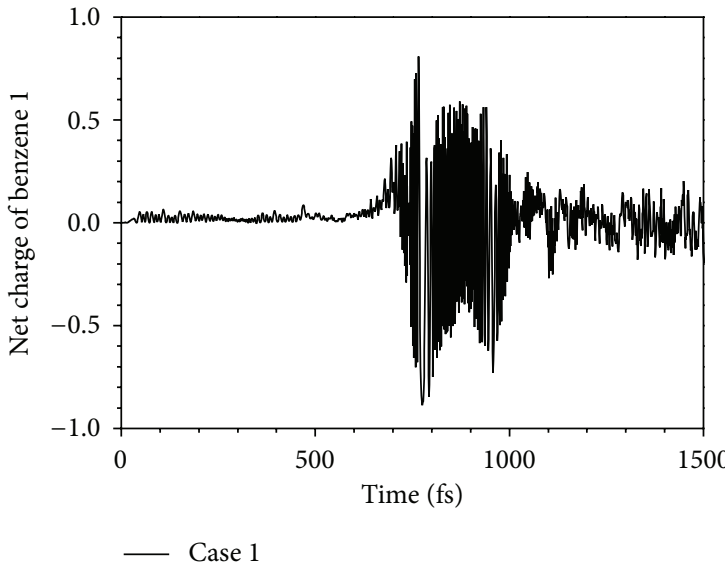

(a)

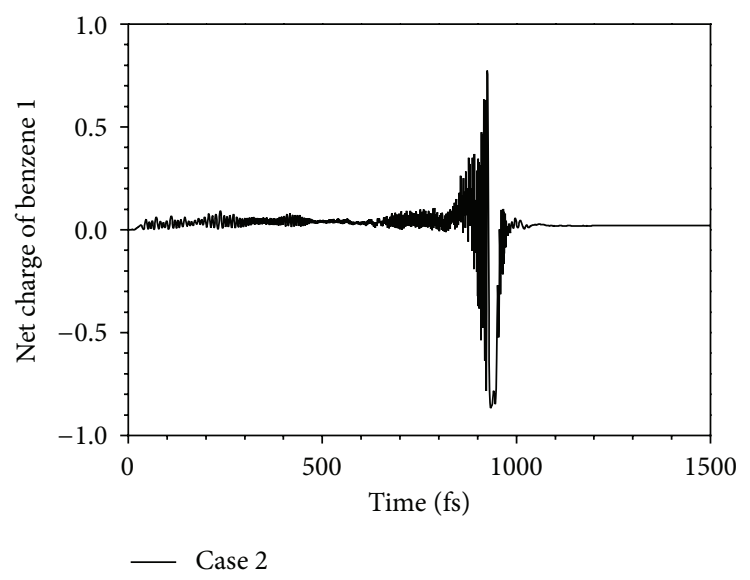

(c)

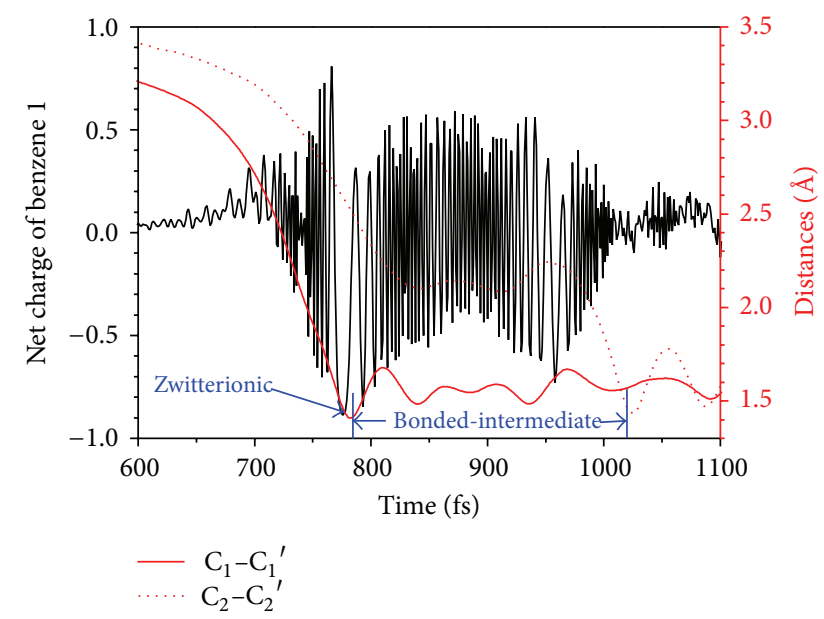

(b)

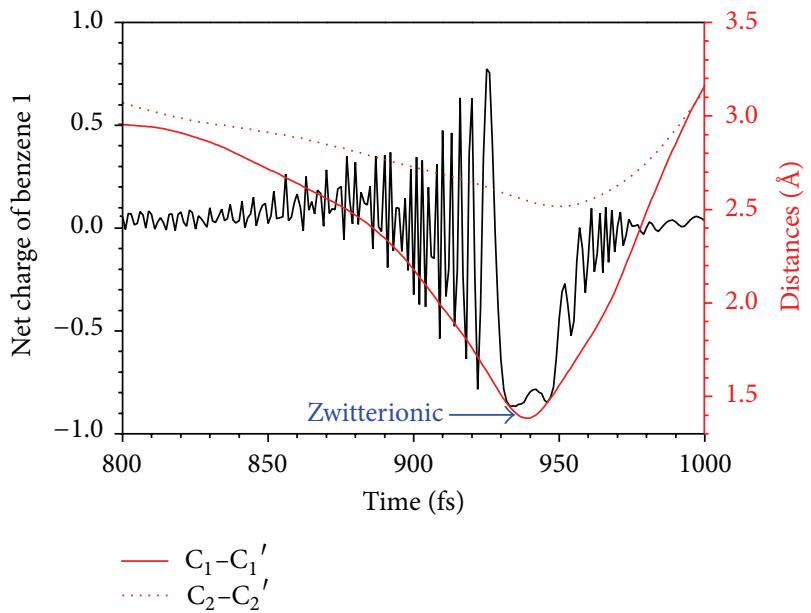

(d)

FIGURE 10: The net charge of benzene 1 molecule of (a) Case 1 and (c) Case 2. Here (b) is the detail of (a) from 600 to $1200 \mathrm{fs}$ and both $\mathrm{C}_{1}-\mathrm{C}_{1}{ }^{\prime}$ and $\mathrm{C}_{2}-\mathrm{C}_{2}{ }^{\prime}$ distances are inserted to compare; (d) is the expanded scale of (c) from 800 to $1000 \mathrm{fs}$ and both $\mathrm{C}_{1}-\mathrm{C}_{1}{ }^{\prime}$ and $\mathrm{C}_{2}-\mathrm{C}_{2}{ }^{\prime}$ distances in that case are inserted.

of $[2+3]$ product seems most probable because of the short $\mathrm{C}_{3}-\mathrm{C}_{2}{ }^{\prime}$ distance.

Classical photoinduced $[2+2]$ cycloadditions proceed via a cyclic transition state and are concerted reactions, in which bond breaking and bond formation take place simultaneously and no intermediate state is involved. But for the photoinduced [2+2] dimerization of benzenes, our simulation results show that the $\mathrm{C}_{1}-\mathrm{C}_{1}{ }^{\prime}$ and $\mathrm{C}_{2}-\mathrm{C}_{2}{ }^{\prime}$ bond formations are nonconcerted. The CASSCF calculation suggests that two stacked benzenes decay to the electronic ground state via the $C I$ when the formation of the $C_{1}-C_{1}{ }^{1}$ bond occurs and that the $\mathrm{C}_{2}-\mathrm{C}_{2}{ }^{\prime}$ distance is longer than $\mathrm{C}_{1}-\mathrm{C}_{1}{ }^{\prime}$ at the CI. Therefore, the Woodward-Hoffmann rules do not apply. Our simulations suggest the formation of a "bondedintermediate" at avoided crossing; it involves a charge separation leading to a zwitterion and a "bonded-intermediate." The bonded-intermediate is a necessary intermediate for forming $[2+2]$ product. Otherwise, the zwitterion could reverse to reactant with the breaking of the $\mathrm{C}_{1}-\mathrm{C}_{1}{ }^{\prime}$ bond.

\section{Conclusions}

In this paper, we report a semiclassical dynamics simulation study of the response to ultrashort laser pulses of stacked benzene molecules. The simulation uncovered two different reaction paths, leading to the formation of two different products. The first leads to the formation of cyclobutane benzene dimer and the second eventually returns back to reactants after deactivation. The simulation results can be summarized as follows.

(1) In both reactions, the distances between the $\mathrm{C}_{1}$ and $\mathrm{C}_{1}{ }^{\prime}$ atoms have a great impact on the formation of the avoided crossings, which lead to the deactivation of the photoexcited molecule. Radiationless transformation of both cases occurs when the $\mathrm{C}_{1}$ and $\mathrm{C}_{1}{ }^{\prime}$ atoms form a covalent bond.

(2) In the first reaction, the formation of the two chemical bonds is asynchronous and a time lag is $230 \mathrm{fs}$. A 


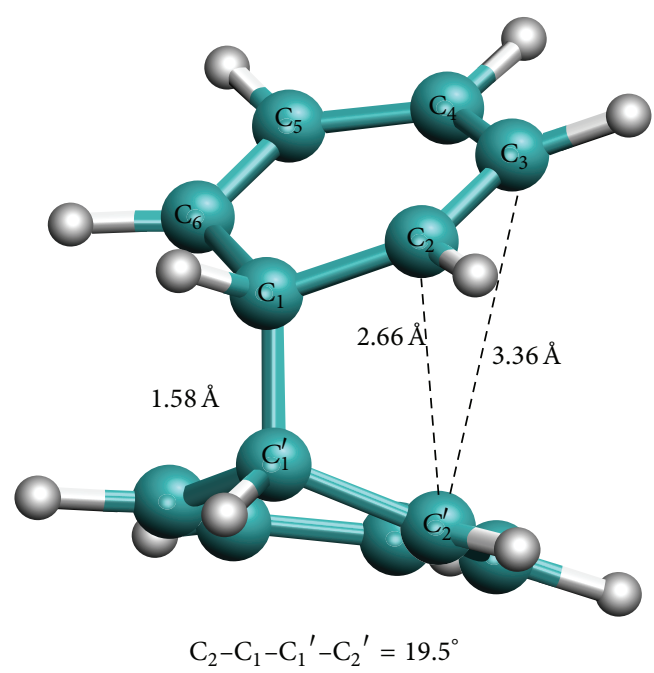

(a)

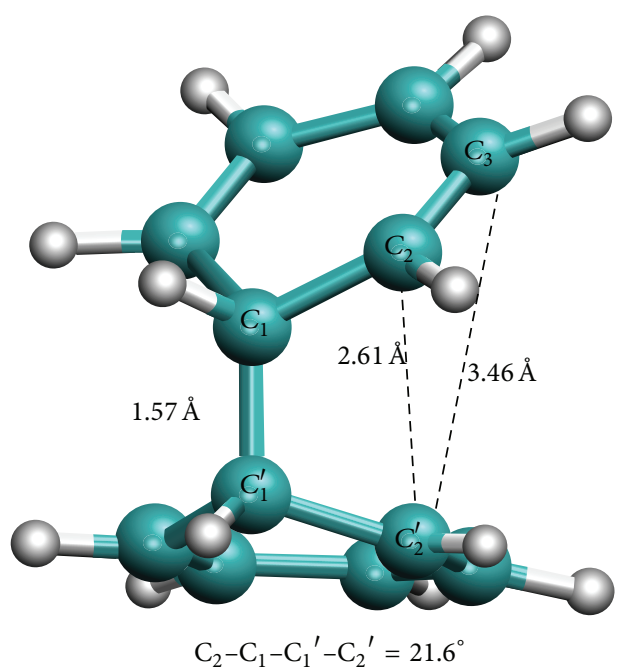

(b)

FIgURE 11: The molecular geometry at avoided crossing of (a) Case 1 and (b) Case 2.

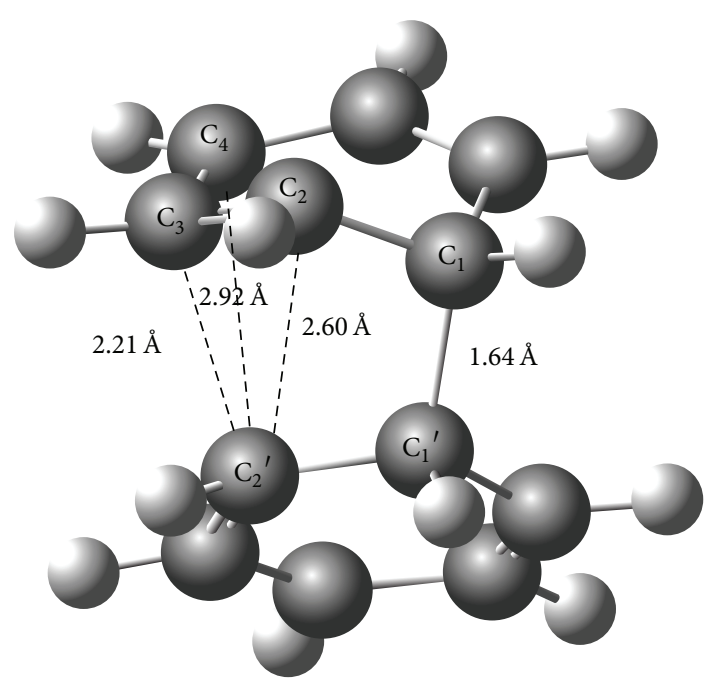

FIGURE 12: The geometry of conical intersection by CASSCF $(12,12) /$ 6-3lg(d) optimization.

bonded-intermediate is observed before the formation of cyclobutane dimer.

(3) In the second reaction, only one bond is formed between two benzene molecules. This bonded-intermediate exists for only $50 \mathrm{fs}$ and possesses significant zwitterionic character. The final product is two separated benzene molecules. The deformation of benzene ring plays an important role in the breaking of this bond.

\section{Conflict of Interests}

The authors declare that there is no conflict of interests regarding the publication of this paper.

\section{Acknowledgments}

This work is supported by the National Natural Science Foundation of China (Grant no. U1330138 and no. 21203259) and the Natural Science Foundation Project of CQ CSTC (cstc2011jjA00009) and Project of the Science Technology Foundation of Chongqing Education Committee, China (nos. KJ120516 and KJ120521).

\section{References}

[1] R. Beukers, A. P. M. Eker, and P. H. M. Lohman, "50 years thymine dimer," DNA Repair, vol. 7, no. 3, pp. 530-543, 2008.

[2] C. E. Crespo-Hernández, B. Cohen, and B. Kohler, "Base stacking controls excited-state dynamics in A-T DNA," Nature, vol. 436, pp. 1141-1144, 2005.

[3] C. T. Middleton, K. de la Harpe, C. Su, Y. K. Law, C. E. CrespoHernández, and B. Kohler, "DNA excited-state dynamics: from single bases to the double helix," Annual Review of Physical Chemistry, vol. 60, pp. 217-239, 2009.

[4] M. Boggio-Pasqua, G. Groenhof, L. V. Schäfer, H. Grubmüller, and M. A. Robb, "Ultrafast deactivation channel for thymine dimerization," Journal of the American Chemical Society, vol. 129, no. 36, pp. 10996-10997, 2007.

[5] N. Hoffmann, "Photochemical reactions as key steps in organic synthesis," Chemical Reviews, vol. 108, pp. 1052-1103, 2008.

[6] U. Streit and C. G. Bochet, "The arene-alkene photocycloaddition," Beilstein Journal of Organic Chemistry, vol. 7, pp. 525-542, 2011.

[7] K. E. Wilzbach, J. S. Ritscher, and L. Kaplan, "Benzvalene, the tricyclic valence isomer of benzene," Journal of the American Chemical Society, vol. 89, no. 4, pp. 1031-1032, 1967.

[8] L. Kaplan and K. E. Willzbach, "Photolysis of benzene vapor. Benzvalene formation at wavelengths 2537-2370 A," Journal of the American Chemical Society, vol. 90, no. 12, pp. 3291-3292, 1968. 
[9] E. E. van Tamelen and S. P. J. Pappas, "Chemistry of dewar benzene. 1,2,5-Tri-t-butylbicyclo[2.2.0]Hexa-2,5-diene," Journal of the American Chemical Society, vol. 84, pp. 3789-3791, 1962.

[10] E. E. van Tamelen and S. P. Pappas, "Bicyclo[2.2.0]hexa-2,5diene [3]," Journal of the American Chemical Society, vol. 85, no. 20, pp. 3297-3298, 1963.

[11] D. Bryce-Smith, "Orbital symmetry relationships for thermal and photochemical concerted cycloadditions to the benzene ring," Journal of the Chemical Society D, no. 14, pp. 806-808, 1969.

[12] J. A. van der Hart, J. J. C. Mulder, and J. Cornelisse, "Funnels and barriers in the photocycloaddition of arenes to alkenes and dienes," Journal of Photochemistry and Photobiology A, vol. 86, no. 1-3, pp. 141-148, 1995.

[13] S. Clifford, M. J. Bearpark, F. Bernardi, M. Olivucci, M. A. Robb, and B. R. Smith, "Conical intersection pathways in the photocycloaddition of ethene and benzene: a CASSCF study with MMVB dynamics," Journal of the American Chemical Society, vol. 118, no. 31, pp. 7353-7360, 1996.

[14] J. J. Serrano-Pérez, F. de Vleeschouwer, F. de Proft, D. MendiveTapia, M. J. Bearpark, and M. A. Robb, "How the conical intersection seam controls chemical selectivity in the photocycloaddition of ethylene and benzene," Journal of Organic Chemistry, vol. 78, no. 5, pp. 1874-1886, 2013.

[15] J. J. McCullough, "Photoadditions of aromatic compounds," Chemical Reviews, vol. 87, no. 4, pp. 811-860, 1987.

[16] D. Döpp, "Photocycloaddition with captodative alkenes," in Organic, Physical and Materials Photochemistry, V. Ramamurthy and K. S. Schanze, Eds., vol. 6 of Molecular and Supramolecular Photochemistry, pp. 101-148, Marcel Dekker, New York, NY, USA, 2000.

[17] K. Mizuno, H. Maeda, A. Sugimoto, and K. Chiyonobu, "Molecular and supramolecular photochemistry," in Understanding and Manipulating Excited-State Processes, V. Ramamurthy and K. S. Schanze, Eds., vol. 8, p. 127, Marcel Dekker, New York, NY, USA, 2001.

[18] D. Döpp, C. Krüger, H. R. Memarian, and Y.-H. Tsay, "1,4-photocycloaddition of $\alpha$-morpholinoacrylonitrile to 1-acylnaphthalenes," Angewandte Chemie International Edition in English, vol. 24, no. 12, pp. 1048-1049, 1985.

[19] H. Meier and D. Cao, "Optical switches with biplanemers obtained by intramolecular photocycloaddition reactions of tethered arenes," Chemical Society Reviews, vol. 42, pp. 143-155, 2013.

[20] A. Y. Rogachev, X.-D. Wen, and R. Hoffmann, "Jailbreaking benzene dimers," Journal of the American Chemical Society, vol. 134, no. 19, pp. 8062-8065, 2012.

[21] Y. Dou, B. R. Torralva, and R. E. Allen, "Semiclassical electronradiation-ion dynamics (SERID) and cis-trans photoisomerization of butadiene," Journal of Modern Optics, vol. 50, no. 15-17, pp. 2615-2643, 2003.

[22] Y. Dou, B. R. Torralva, and R. E. Allen, "Gas phase absorption spectra and decay of triplet benzene, benzene- $d_{6}$, and toluene," Chemical Physics Letters, vol. 392, no. 4, pp. 352-358, 2004.

[23] W. Zhang, S. Yuan, A. Li, Y. Dou, J. Zhao, and W. Fang, "Photoinduced thymine dimerization studied by semiclassical dynamics simulation," The Journal of Physical Chemistry C, vol. 114, no. 12, pp. 5594-5601, 2010.

[24] S. Yuan, W. Zhang, L. Liu, Y. Dou, W. Fang, and G. V. Lo, "Detailed mechanism for photoinduced cytosine dimerization: a semiclassical dynamics simulation," The Journal of Physical Chemistry A, vol. 115, no. 46, pp. 13291-13297, 2011.
[25] M. Ben-Nun and T. J. Martínez, "Ab Initio quantum molecular dynamics," Advances in Chemical Physics, vol. 121, pp. 439-512, 2002.

[26] W. Domcke, D. R. Yarkony, and H. Koppel, Eds., Conical Intersections: Electronic Structure, Dynamics, and Spectroscopy, World Scientific, Singapore, 2004.

[27] M. Baer, Beyond Born-Oppenheimer: Electronic Nonadiabatic Coupling Terms and Conical Intersections, Wiley-Interscience, Hoboken, NJ, USA, 2006.

[28] M. J. Bearpark, F. Bernardi, S. Clifford, M. Olivucci, M. A. Robb, and T. J. Vreven, "The lowest energy excited singlet states and the cis-trans photoisomerization of styrene," Journal of the American Chemical Society, vol. 101, no. 2, pp. 3841-3847, 1997.

[29] B. G. Levine and T. J. Martínez, "Isomerization through conical intersections," Annual Review of Physical Chemistry, vol. 58, pp. 613-634, 2007.

[30] J. Frank, Introduction to Computational Chemistry, John Wiley \& Sons, Chichester, UK, 2007.

[31] C. J. Cramer, Essentials of Computational Chemistry, John Wiley \& Sons, Chichester, UK, 2002.

[32] M. J. Frisch, G. W. Trucks, H. B. Schlegel et al., Gaussian 09, Revision D01, Gaussian, Wallingford, Conn, USA, 2010.

[33] S. Tsuzuki, "Interactions with aromatic rings," Structure and Bonding, vol. 115, pp. 149-193, 2005.

[34] K. C. Janda, J. C. Hemminger, J. S. Winn, S. E. Novick, S. J. Harris, and W. Klemperer, "Benzene dimer: a polar molecule," The Journal of Chemical Physics, vol. 63, no. 4, pp. 1419-1421, 1975.

[35] J. M. Steed, T. A. Dixon, and W. Klemperer, "Molecular beam studies of benzene dimer, hexafluorobenzene dimer, and benzene-hexafluorobenzene," The Journal of Chemical Physics, vol. 70, no. 11, pp. 4940-4946, 1979.

[36] E. Arunan and H. S. Gutowsky, "The rotational spectrum, structure and dynamics of a benzene dimer," The Journal of Chemical Physics, vol. 98, no. 5, pp. 4294-4296, 1993.

[37] W. Scherzer, O. Kratzschmar, H. L. Selzle, and E. W. Schlag, "Structural isomers of the benzene dimer from mass selective hole-burning spectroscopy," Zeitschrift für Naturforschung A, vol. 47, pp. 1248-1252, 1992. 

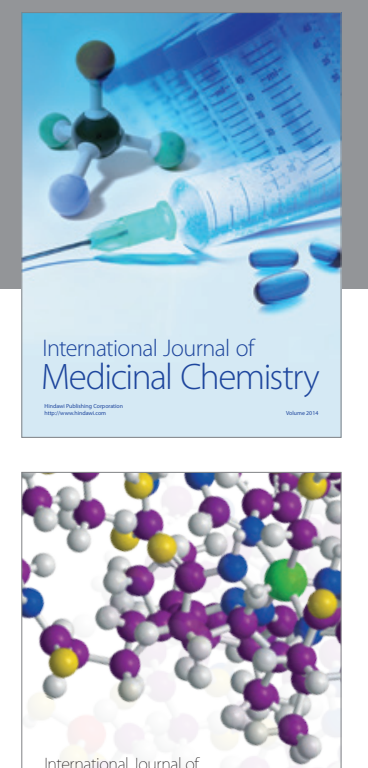

\section{Carbohydrate} Chemistry

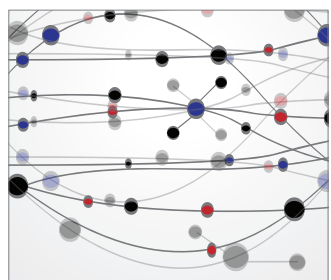

The Scientific World Journal
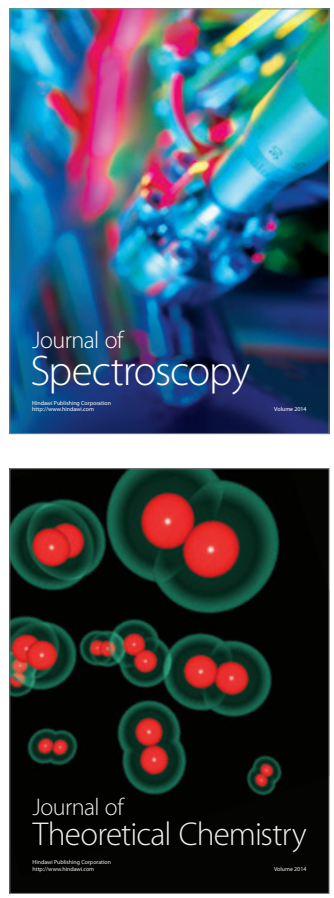
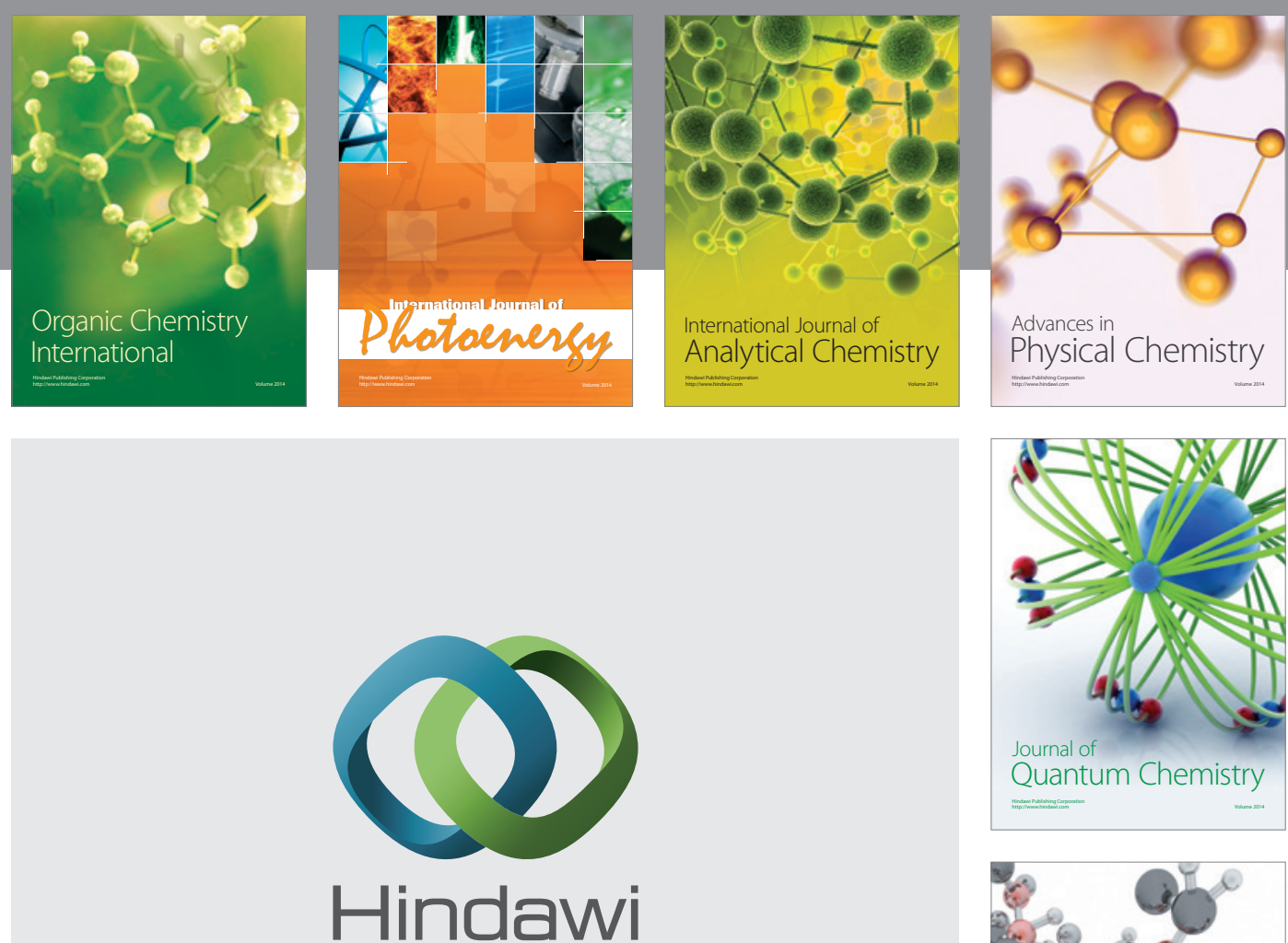

Submit your manuscripts at

http://www.hindawi.com

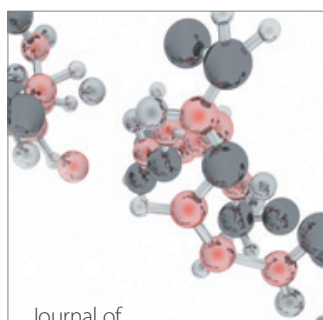

Analytical Methods

in Chemistry

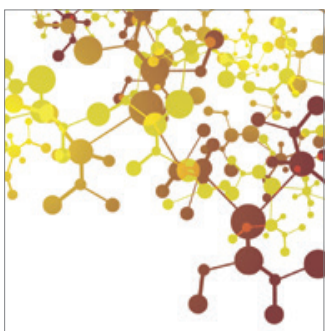

Journal of

Applied Chemistry

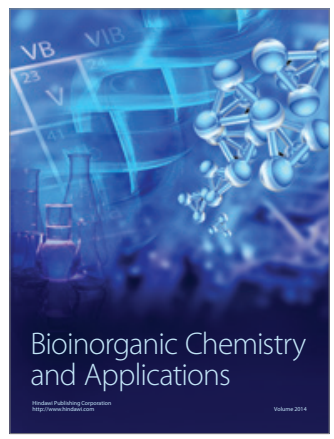

Inorganic Chemistry
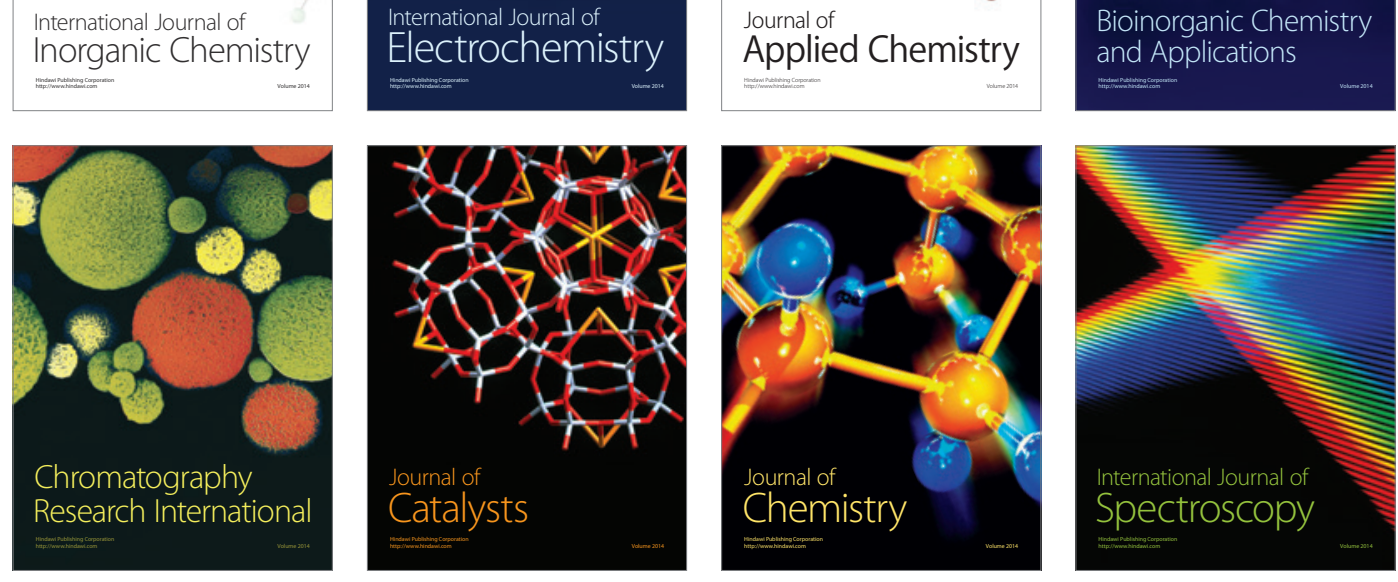